\title{
A CIDADE E SUAS REPRESENTAÇÕES: Manaus no século XIX (1850- 1883)
}

Bruno Miranda Braga*

RESUMO: O objetivo central deste artigo é discutir e apresentar elementos que evidenciem as práticas cotidianas de uma cidade: Manáos na segunda metade do século XIX, que se tornara um local de sociabilidades múltiplas, onde uma miscelânea de pessoas do além-mar resolvera tomá-la como local para residência, ou geração de renda. Nessa perspectiva, a visão dos "de fora" se distancia e muito da elite local, pois para esta última, a cidade ostentava o "orgulha da civilização" e seus habitantes todos já haviam deixados para trás os costumes e hábitos da Manáos de outrora, ligada ao atraso, ao incivil, ao rio e aos indígenas. Partimos especialmente da análise iconográfica presente no álbum souvenir da Exposição de Chicago de 1883, onde Manaus foi apresentada como um lugar de riqueza e civilização e o entorno da Província, um lugar de ruralismo e natureza extensa. Assim, destacaremos o cotidiano dessa cidade, cotidiano este marcado por diferentes "formas de fazer".

PALAVRAS-CHAVE: Manaus; Século XIX; Belle Époque; Cidade.

\section{The City and its representations: Manaus in the Nineteenth Century (1850- 1883)}

ABSTRACT: The main objective of this article is to discuss and present data showing the everyday practices of a city: Manáos in the second half of the nineteenth century, which had become a place of multiple sociability, where a mix of people from overseas decided it as a place for residence, or income generation. In this perspective, the vision of the "outside" is distant and the local elite, as to the latter, the city boasted the "pride of civilization" and its inhabitants all had left behind the customs and habits of Manáos of old, connected to the delay, the uncivil, the river and the indigenous. We leave especially the iconographic analysis in this souvenir album of the Chicago Exposition of 1883, which Manaus was presented as a place of wealth and civilization and the environment of the province, a place of rurality and extensive nature. Thus, we will highlight the everyday life of this city, this routine marked by different "ways of doing."

KEYWORDS: Manaus; XIX century; Belle Époque; City.

\section{La ciudad y sus representaciones: Manaus, en el Siglo XIX (1850- 1883)}

RESUMEN: El objetivo principal de este artículo es discutir y presentar los datos que muestra las prácticas cotidianas de una ciudad: Manáos en la segunda metada del siglo XIX, que se había convertido en un lugar de sociabilidad múltiple, en donde una mezcla de personas desde el extranjero decidió tomá-la como un lugar de residencia, o la generación de ingresos. En esta perspectiva, la visión del "exterior" es distante y la élite local, en cuanto a esta última, la ciudad contó con la "orgullo de la civilización" y sus habitantes todos habían dejado atrás las costumbres y hábitos de Manáos de edad, conectado a la demora, no civil, el río y la indígena. Dejamos en especial el análisis iconográfico en este álbum del recuerdo de la Exposición de Chicago de 1883, lo que Manaos se presentó como un lugar de la riqueza y de la civilización y el medio ambiente de la provincia, un lugar de la ruralidad y la extensa naturaleza. Por lo tanto, vamos a destacar la vida cotidiana de esta ciudad, esta rutina marcada por diferentes "formas de hacer".

PALABRAS-CLAVE: Manaus; Siglo XIX; Belle Époque; Ciudad.

\footnotetext{
*Mestre em História Social pelo Programa de Pós-Graduação em História da Universidade Federal do Amazonas/PPGH-UFAM. Membro do Grupo de Pesquisa em Cultura e Historiografia da Amazônia- CAHIAM, e do Núcleo de Estudos de História Social da Cidade -NEHSC. E-mail: brunomirandahistor@ hotmail.com.
} 
São José da Barra, cheios de adornos e miçangas indígenas.

A belle époque constitui-se de um período que se inicia na segunda metade do século XIX, ou seja, por volta de $1850 \mathrm{ou}$, convencionalmente, no decurso desta segunda metade do XIX. Um dos destaques da Belle Époque são as melhorias e reformas urbanas como a reurbanização de Paris pelo Barão de Haussmann. ${ }^{1}$ Ao mostrar o ideal de urbanização de Haussman, Walter Benjamin enfatiza o momento em que Paris vivia uma fase de intensa especulação. Benjamin, também informa que Haussman, se autodenominava de "artista demolidor", pois este foi o responsável pela nova Paris, que se tornou estranha para seus próprios habitantes. Em Manaus, a elite e dos coronéis da borracha e alguns políticos seguiram os passos do "artista demolidor", para executar seu plano embelezador. ${ }^{2}$

A vida feliz e alegre das nações enriquecidas será parte do discurso construído sobre esse período. Belle Époque é um momento histórico onde a visão progressista assume papel primordial em todos os setores das atividades humanas, nesse momento, o homem acredita que tudo pode alcançar, tudo pode fazer. Marcado pela profunda arrogância das nações europeias que enriqueceram pela exploração imperialista de suas colônias nas Américas, na África ou na Ásia, a Europa vai ostentar o orgulho da civilização e será a partir dessa pompa e crença, bem como pelo discurso progressista que a Belle Époque se cristalizará como momento de grande euforia à medida que nas artes, se destacarão o Can-Can, o Art Nouveau, as festas e alegrias dos banquetes e bailes franceses, a vida boêmia da noite.

O que no léxico da História Cultural ficou configurado como belle époque indica um complexo processo de relações culturais, sociais e mentais, mas também materiais e políticas, desenvolvidas no interior de um corpus reconhecido historicamente como o da cultura burguesa e da sua afirmação no interior dos quadros hegemônicos do capitalismo industrial no final do século XIX. ${ }^{3}$

Nesse sentido, a belle époque pode ser vista, aceita como um período de festas e divertimentos, se lançarmos nosso olhar a partir das elites, porém, verificamos que há nessa fase um encobrimento por parte dessa elite com relação aos pobres. Nisso, ao mudarmos nosso olhar para a população menos abastada, vemos lutas, ressignificações, e reinvenções cotidianas no meio do discurso da alegria!

A belle époque, em última análise, edulcorou a dramática dialética da revelação e do encobrimento, da aparência e da essência, no limite em que, segundo o pensamento marxista, tudo o que era sólido se evaporava no ar na Paris fin de siècle. ${ }^{4}$ 
Ao adentrar o segundo quartel do século XIX, o Amazonas torna-se província do Império do Brasil. Nesse período, Manaus ainda não tinha sofrido o surto de urbanização pela qual passaria. Em 1862, Manaus não passava de uma pequena vila, pouco povoada, pouco organizada e pouco urbanizada, como vemos nas imagens seguintes, extraídas do livro de Auguste François Biard, que foi um naturalista e pintor francês que percorreu todo o Império do Brasil registrando através de aquarelas aquilo que despertava sua atenção, aspectos da natureza do Império nascente. Inicialmente pintou retratos da Família Imperial no Rio de Janeiro, de lá passou pela Província do Espírito Santo, chegando na Amazônia, na Cidade de Belém, capital da Província do Pará e até Manaus, onde apresentou um pouco do cotidiano de então. De Manáos partiu para a região do Madeira e de lá regressou à Belém para então retornar a Europa em 1859. De suas anotações, em 1862, foi publicado em Paris o livro Deux années au Brésil, que contem rico acervo iconográfico das terras brasileiras do período. ${ }^{5}$ Porém, tais ilustrações são de autoria do seu colaborador Eduard Riou que o acompanhou em viagem. Por não ter formação de um naturalista, sua obra teve pouca relevância científica. As imagens que seguem, apresentam um olhar sobre a paisagem da cidade no início da segunda metade do século XIX.

Figura 1: La forêt près de Manáos

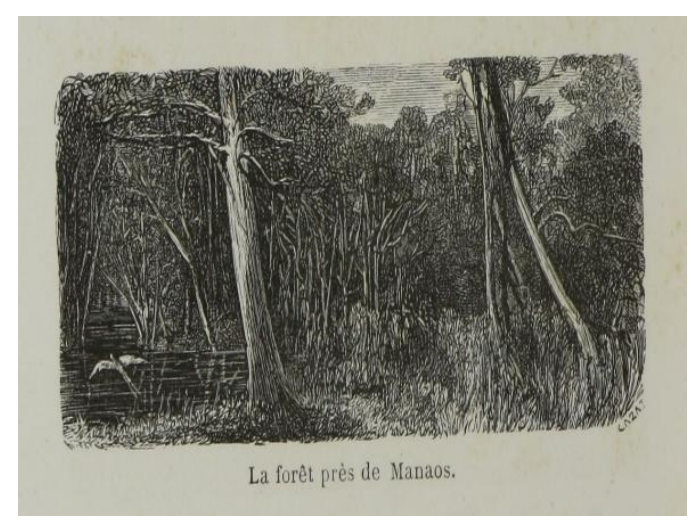

Figura 2: Le canot devant Manaos.

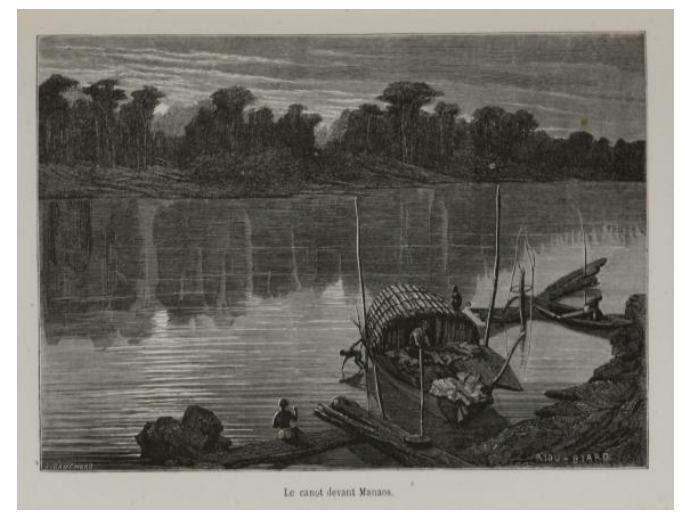

Fonte: BIARD, Auguste François

Nelas, vemos a paisagem, a Geografia, a natureza da cidade de Manáos, uma cidade pequena, cercada por florestas típicas de sua localização, rios caudalosos, canoas como meios de transporte, tudo isso era normal e corriqueiro na vivência local.

Toda essa natureza representada pelo autor, caracteriza a cultura citadina e os ethos locais serão regidos por essa natureza peculiar de então, ao ponto de até mesmo os próprios 
estrangeiros viajantes que por aqui passaram, se imbuírem em atividades locais como dormir em redes, banhar-se em igarapés, alimentar-se de frutos e peixes exóticos de então, etc.

Outros viajantes naturalistas percorreram o vale amazônico, descrevendo seus rios, fauna e flora, geografia e etnografia. Entre 1848 e 1860, o francês Paul Marcoy viajou e explorou o Alto e Baixo Amazonas. O mesmo, assim descreveu a então Barra do Rio Negro:

\begin{abstract}
A cidade moderna em que acabamos de chegar é chamada pelos brasileiros A Barra do Rio Negro. Situa-se a leste da fortaleza, a cerca de mil passos geométricos do sitio de Manáos. Ela está constituída numa superfície tão irregular que chega a ter morrinhos mais altos do que os telhados das casas, o que seria pitoresco se não fosse absurdo. Uma longa avenida, larga e ondulada, estreitada aqui e acolá por muros desalinhados e sacadas proeminentes, corta a cidade de norte a sul. Algumas vielas saem desta rua em direção ao leste. Enquanto a oeste há uma série de grandes espaços vazios. Três riachos providos de passarelas serpenteiam pela cidade e servem de docas e estaleiros para a sua flotilha mercantil. Pequenas escunas, chalupas e canoas cobertas estão em reparo, aguardam algum carregamento ou se abrigam das trovoadas, essas tempestades brasileiras que assolam o baixo Amazonas e cuja influência é sentida muitas léguas acima pelo rio $\mathrm{Negro}^{6}$
\end{abstract}

Com este excerto temos uma provável visão de Manaus há 150 anos. A vila era formada em um espaço com geografia difícil, igarapés cortavam-na por todos os lados, o relevo era alto com grandes elevações de planaltos e morros. Entendemos paisagem como uma primeira visão que um sujeito tem com os lugares, ambientes, “isto é, com as maneiras pelas quais seus sentidos se apropriam das sensações, mas, ainda, elas não possuem um sentido próprio. É, em outras palavras, o contato com a aparência dos lugares. " 7 Para Milton Santos, geógrafo brasileiro, “[...] A paisagem nada tem de fixo, de imóvel. Cada vez que a sociedade passa por um processo de mudança, a economia, as relações sociais e políticas também mudam, em ritmos e intensidades variados. "8

A paisagem considera sempre parte de um processo de associação, mas é, ao mesmo tempo, contínua no espaço e no tempo, é básica sem ser totalizante, resulta sempre de uma mistura, um mosaico de tempos e objetos datados, de formas e práticas. A paisagem pressupõe, também, um conjunto de formas e funções em constante transformação, seus aspectos "visíveis", mas, por outro lado, as formas e as funções indicam a estrutura espacial, em princípio, "invisível”, e resulta sempre do casamento da paisagem com a sociedade. Sendo assim, a paisagem, destacada pelo viajante, constitui-se de uma visão preliminar, algo de imediato, e algo que estava presente à vista de todos que chegassem a cidade. Nesse mesmo período, Marcoy nos diz que a vila é habitada por três mil almas, dois terços das quais constituem a população permanente e os demais a temporária. O número de casas é avaliado 
em 147. ${ }^{9}$ Apenas três mil habitantes e 147 casas, vale destacar aqui como se compunha essa população, em sua maioria índios e mamelucos.

Lourenço da Silva Araújo e Amazonas nos informa que em 1852 Manaus possuía 8.500 habitantes, ou seja, poucos anos após a descrição de Marcoy podemos perceber que houve um crescimento populacional, se os dados forem confiáveis. Destes 8.500 moradores, 4.080 eram índios, 2.500 mamelucos, 900 brancos, 640 mestiços e 380 escravos. $^{10}$

Vemos como a Barra do Rio Negro tentara se despir de tudo que lembrara outrora, em que era Fortaleza de São José. ${ }^{11} \mathrm{O}$ viajante estabelece uma comparação com cunho evolutivo e classificatório que destaca a paisagem da Barra em detrimento das demais localidades por onde ele passou. Neste momento e em todo o século XIX, a ideia de evolução esteve em voga na teoria darwinista ou Teoria da Evolução que no meio das ciências humanas e sociais, ganhou uma vertente denominada Darwinismo Social e com o avanço da Escola Positivista tivera repercussão e aceitação no meio acadêmico. Pela fala do viajante, percebemos um tom que enfatiza essa visão que vê nos costumes tipicamente indígenas latentes em outras localidades no Vale Amazônico um reino de barbárie e a Barra que apesar de sua topografia e geografia difíceis já se encontra num "estágio de superioridade" se comparada ao restante do Amazonas. Mas o viajante faz questão de salientar e descrever as "paisagens notáveis" presentes no perímetro urbano da cidade, expondo sua visão idílica das paisagens presentes na cidade. Reitero que entendo paisagem como o contato com as aparências do lugar, logo na perspectiva do viajante, a cidade mesmo distante da dita barbárie, preserva em seu interior e entorno elementos naturais os quais Marcoy desfruta como se fosse um paraíso verde, uma sinfonia natural quase onírica se não fosse ocorrente. Marcoy, faz referência a Fortaleza da Barra do Rio Negro. Uma fortificação militar portuguesa erguida na Barra do Rio Negro ainda no século XVII. A figura seguinte, extraída do relato de Paul Marcoy representa um possível estado da tal Fortaleza durante a sua passagem pela cidade.

Vale destacar que a visão do viajante Marcoy assim como de quase todos os que passaram pela cidade, é uma realidade exótica, uma representação veiculada à um discurso específico, aquilo que era diferente de sua terra natal pois, eles narravam o que lhes chamava a atenção constituindo-se suas falas como visões de algo que era comum a população local, mas estranho para eles. Podemos acreditar que além do discurso modernizador e evolucionista da época, as vivências dos viajantes somam-se aos discursos que mudarão ou tentarão mudar as características da cidade quer sejam culturais, quer geográficas e topográficas. 
Outros viajantes, já apostavam que Manaus logo seria um importante centro comercial e cultural também. Louis e Elisabeth Agassiz, um casal de naturalistas que viajavam a serviço dos Estados Unidos, em 1866, assim apontaram um futuro para Manaus. “[...]. Insignificante hoje, Manaus se tornará, sem dúvida, um grande centro de comércio e navegação. Mas quando na imensa vastidão de terras cobertas ainda por florestas impenetráveis, nas consideráveis dificuldades que impedem a criação de povoações nessa região - insetos, clima, comunicações difíceis [...]. " ${ }^{12}$ Em sua descrição, Manaus é citada como uma cidade sem as mínimas condições de urbanidade e em completo desleixo urbano.

Louis Agassiz chefiou a expedição cientifica norte-americana que visitou o Brasil no período 1865-1866. Dessa expedição, composta de umas quinze pessoas e financiada por Nathaniel Thayer, participou também, Elisabeth Cary Agassiz, que registrou, dia a dia, o ocorrido com todos. Os elementos para a confecção de seu registro eram fornecidos diariamente, pelo naturalista. Esse diário, com pequenas modificações, é que foi publicado, mais tarde, por Louis e Elisabeth Cary.

Em seu diário de viagens, encontramos versões de como a cidade e seus habitantes estavam inseridos num cotidiano peculiar. As próprias elites da cidade apresentavam em seus hábitos, elementos que ainda se filiavam aos costumes indígenas, muito presente na cidade no Império e em todo o oitocentos.

Na visão de François Biard, como de outros viajantes que percorram o Vale Amazônico, Manáos era um lugar onde o tempo e seu ritmo possuíam peculiaridades sem igual, fora que por sua gente "vermelha", e suas edificações e construções públicas, "Manáos não possuía glamour. "E isso muitas vezes, foi expresso de forma jocosa pelos que visitaram a cidade.

Figura 03: Maison du président de Manaos (Casa do Presidente de Manáos)

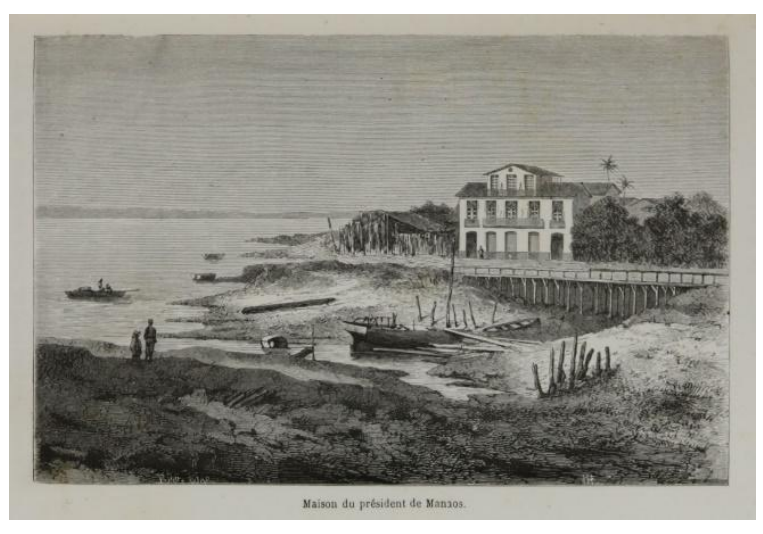

Fonte: BIARD, Auguste François, 1798-1882 ${ }^{13}$ 
A gravura acima que representa a Casa do Presidente da Província do Amazonas, em 1862. Quatro anos mais tarde, ao passar pela cidade o casal Louis e Elisabeth Agassiz possivelmente encontraram a cidade no mesmo estado, e, seus edifícios públicos na mesma situação. Agora voltemos nossa atenção a paisagem de Manáos em 1862 a partir da imagem acima: uma cidade com vegetação tropical latente, ruas sem aplainamentos e sem asfaltos ou pavimentações, e, a referida casa do então presidente da província, as margens do rio, sem grandes ornamentos. A cidade, apresenta pela fotografia poucos transeuntes, canoas, que eram o principal meio de transporte de então, e uma ponte de madeira. O interessante nisso tudo é a permanência, a foto é de 1862, Louis e Elisabeth Agassiz, passam por aqui em 1866, e, se deparam com uma cidade que lhe causa grande muito espanto. A decoração de seus prédios públicos causa riso em Elisabeth e Louis a ponto de os mesmos enfatizarem que a única coisa positiva da cidade é sua posição geográfica que poderá leva-la a ser um importante centro comercial.

Outro ponto é o fato da população residente em Manáos ser pequena e a mesma possuir uma população transeunte maior que a fixa, pois o casal de viajantes sugere estar longe o dia em que uma população numerosa irá se fixar na cidade. Um terceiro ponto que faço destaque é a espécie de grande loteamento da cidade que o casal aponta "todas as nações do globo venham buscar a sua parcela', é como se os recursos naturais da cidade e de seu entorno não fossem usados pela sua população permanente. Na visão do casal Agassiz, em Manaus, "a natureza estava pronta, mas seu habitante não." ${ }^{14} \mathrm{O}$ seu habitante não estava preparado devido a sua raça e sua cor. Essa visão perdurou por muito tempo. ${ }^{15}$

Os habitantes da cidade da Barra do Rio Negro dedicaram-se basicamente ao comércio, sendo de cunho atacadista ou varejista, segundo relatos do período. A sociabilidade de Manaus ocorria em constante harmonia. Marcoy diz que apesar de toda a geografia peculiar da cidade da Barra, a cidade dava uma impressão agradável e nela, segundo o viajante, não existia ou pouco reinava a barbárie que imperava em outras localidades dispersas pelo Rio Amazonas. ${ }^{16}$

Berman nos diz que a experiência ambiental da modernidade rompe qualquer fronteira geográfica. ${ }^{17}$ Mesmo Manaus estando bem distante da França, foi inevitável ser transformada aos moldes franceses. A modernidade também, "une a espécie humana. Porém, é uma unidade paradoxal, uma unidade de desunidade: ela nos despeja a todos num turbilhão de permanente desintegração e mudança, de luta e contradição, de ambiguidade e angústia. " ${ }^{18}$ Vale destacar 
a velocidade, a rapidez com que as transformações acontecem. Cito como exemplo o nome da cidade: segundo Otoni Mesquita, “em 1848, a vila de Manaus foi promovida a cidade, passando a denominar-se cidade da Barra do Rio Negro [...]". 19

Uma das principais categorias de análise da Nova História Cultural, é o Cotidiano. O cotidiano é um complexo onde há uma multiplicidade de fazeres agindo sobre o mesmo espaço/tempo. Michel de Certeau, estabeleceu uma análise sobre o cotidiano. Para ele, a construção do cotidiano dá-se por meio de dois tipos de produção:

[...] a produção expansionista além de centralizada, barulhenta e espetacular, corresponde outra produção, qualificada de "consumo": esta é astuciosa, é dispersa, mas ao mesmo tempo ela se insinua ubiquamente, silenciosa e quase invisível, pois não se faz notar com produtos próprios, mas nas maneiras de empregar os produtos por uma ordem econômica dominante. ${ }^{20}$

Citei a pouco que os índios já usavam camisas, essa transformação agiu dentro da lógica dos limites ditados por outros. Mas as formas de utilização destas normas não foram lineares, muito menos utilizadas em sua forma propriamente dita, isso é o que Certeau chama de tática, e a tática age na lógica do poder dominante, não há sangue, não há guerra, há uma “aceitação” que será resignificada por quem irá reutilizá-la.

Assim como os índios passaram a usar camisas, os estrangeiros, como o viajante acima citado, passaram a agir com algumas características que são elementares a cultura indígena. Tomar banho diariamente no mundo "branco" era coisa de libertinos de imorais imundos; já no meio dos índios o banho diário é um costume que é utilizado como forma oportuna de se refrescar em meio ao calor do clima tropical. Na fala de Marcoy, também observamos dois outros elementos tipicamente da cultura indígena: a rede e a sesta. A rede foi utilizada pelo viajante como cama e poltrona, pois sua presença era comum em diversas residências dos membros da elite local.

O interessante dos relatos desses viajantes aqui citados é que mesmo opondo-se a tudo que acreditavam ser correto e civilizado, eles atuaram como partícipes de tais práticas e, mesmo vivendo numa espécie de fuga, pois no mundo civilizado ao qual frequentavam tais feitos seriam motivos de ofensa e incivilidade, eles fizeram desses momentos coisas oportunas ao seu bem-estar, agraciando-se com esses momentos.

Com isso, vemos mais uma vez como se dava a sociabilidade entre os índios e estrangeiros, que habitavam Manáos, nesse momento, uma constante mistura de elementos e de práticas cotidianas. Muito distante da realidade estrangeira que tentara se implantar entre 
eles. Por isso, o índio luta e resiste. ${ }^{21}$ Na belle époque, será constante na vida da cidade ver elementos oriundos na cultura indígena sendo praticados em Manáos. Caberá aos meios públicos tentarem romper com essas práticas que, como veremos faziam parte da paisagem citadina. O próprio casal Agassiz descreve como o elemento indígena era presente em Manáos quando num passeio em,

18 de novembro- É impossível passear fora da cidade, em qualquer direção, sem observar um traço característico dos habitantes da terra e de seus costumes. Esta manhã, por volta das sete horas, dava eu o meu passeio habitual pela floresta vizinha de nossa casa, à beira de um igarapé, teatro habitual de todas as casas da vida exterior. Aí se reúnem os pescadores, as lavadeiras, os banhistas, os aparadores de tartarugas. $^{22}$

Na descrição de Elisabeth, verificamos mais uma vez como se constituía a cidade de Manáos e seu entorno: uma cidade ribeirinha, com densa floresta circunvizinha. Outro detalhe em sua narrativa é a sociabilidade cabocla e peculiar da cidade: uma reunião de pessoas possivelmente indígenas, realizando seus ofícios diários: pescando, lavando, tomando banhos, ou caçando tartarugas, que além de alimento sua banha era utilizada como querosene nas casas e vias pública.

Reitero que os viajantes também participaram das práticas indígenas da cidade, pois era comum. Vemos nesse excerto uma linguagem peculiar, com termos tipicamente indígenas presentes no cotidiano citadino ao ponto de viajantes estrangeiros fazerem uso em seus relatos desses termos e, com essa cena descrita pelo casal Agassiz, temos uma imagem da presença indígena na sociabilidade citadina, onde fazeres e os próprios tipos indígenas estavam convivendo com uma nova composição social e étnica.

De acordo com o poder público e as elites de então, isso precisava mudar, Manáos precisava deixar de ser uma Tapera, para ser uma cidade civilizada, moderna, ampla. Para isso era preciso mudar radicalmente a fisionomia da cidade, sua natureza seus prédios públicos. Com a descoberta das seringueiras, árvores produtoras da goma elástica, o vale amazônico ganha notoriedade nacional e cobiça internacional. Lembramos agora das palavras do casal Agassiz: "insignificante hoje, Manaus se tornará um grande centro de comércio e navegação..." chegou à belle époque amazônica, Manauara especificamente, que coincide com o que a historiografia convencional local denomina "período áureo da borracha". A exploração de uma espécie nativa, rural, a seringueira, Hevea Brasiliensis, foi a grande proporcionadora da reurbanização pela qual passou a cidade. Na belle époque, a expansão urbanística só foi possível graças à expansão agrária. A reurbanização de várias cidades brasileiras evidencia isso com bastante clareza: São Paulo cultiva o café, juntamente com o 
Rio de Janeiro, Santos. Belém do Pará e Manaus se reurbanizaram à custa da produção gomífera.

A historiadora Simone Villanova nos mostra que em Manaus como em outra cidades e províncias, a preferência pelos lazeres considerados não civilizados era comum e rotineiro. ${ }^{23}$ Acredito que alguns fazeres também eram preferíveis para alguns. Na narrativa de Elisabeth Cary, um cavalheiro que segundo a viajante vivera muito tempo nas tribos indígenas concedeu a liberdade de comerem sem fazer uso dos talheres; para a época, isso seria uma deselegância extrema, mas podemos crer que este cavalheiro, assim como muitos outros ali presentes utilizaram a presença dos indígenas ali para ficarem mais à vontade ao se pôr a mesa.

Com o crescimento dos números da venda da borracha e sua supervalorização, a composição estrangeira veio a reconfigurar-se. Agora, além de portugueses, havia franceses, italianos, sírio-libaneses, japoneses e ingleses em grande escala. Manáos, mais do que nunca, precisava deixar de ser uma aldeia e correr para se tornar Paris, uma cidade moderna que exalasse civilidade, o primeiro ímpeto era romper a cultura indígena, presente nas casas, nos prédios públicos, na paisagem e nos trabalhadores.

Para alcançar os objetivos propostos pelos ideais de civilização e modernidade que a época exigia, tornara-se necessário também resignificar seus habitantes. A reconfiguração espacial, impõem e exige uma mudança nos habitantes inseridos no ambiente da cidade. As elites e os governantes inspirados por tais ideais, começaram a lançar estratégias de detenção e polimento do espaço público.

\section{Entre a cidade mostrada e a cidade vivida.}

Manáos havia mudado, agora suas feições eram de uma cidade que exaltava civilidade aos moldes europeus. A sociedade que enriquecera com a extração da goma elástica, gabavase de que sua cidade, não ficava para trás de qualquer cidade europeia do mesmo período. Esse era o discurso, mas entre a cidade mostrada e a cidade vivida, a cidade do cotidiano, havia uma linha de diferenças avassaladoras. O espaço urbano, criado para apresentar ao mundo e atrair o público estrangeiro, ao mesmo tempo que projeta, riqueza, luxo e civilização, também guarda em seu interior contradições e muitas resistências, ${ }^{24}$ pois: 
cidade, não tendo as mesmas condições de sobrevivência daqueles que vão usufruir a vida do "fausto" que a borracha propicia. [... ${ }^{25}$

Assim, cristalizou-se na historiografia o discurso do belo, e essa perpetuação também se deve as fotografias, aos postais, aos álbuns que circulavam mostrando apenas o lado bonito de Manáos na belle époque, ou apenas lido de uma maneira, sem evidenciar a outra face da imagem, sem se fazer iconoclasmo. O trabalho historiográfico, deve escolher desde seu início que tipo e como vai analisar suas fontes. Sabemos que anteriormente, a fonte histórica era o documento, principalmente o oficial, e este era a garantia da verdade. Com a criação da revista francesa Annales d'Histoire Économique et Sociale, ao documento oficial juntaram-se fontes de natureza diversa, como periódicos, relatos, oralidade e imagens.

$\mathrm{Na}$ modernidade, era realizado um acontecimento internacional, que visava mostrar o que cada localidade possuía de "melhor", eram as Exposições Universais. Francisco Foot Hardman, nos diz que elas representavam o exibicionismo burguês, e, nelas viam-se desde a transparência do vidro, à maleabilidade do ferro. ${ }^{26}$

\begin{abstract}
As exposições universais da segunda metade do século passado e princípios deste constituem certamente um dos rios mais férteis para o estudo da ideologia articulada à imagem da "riqueza das nações". Os catálogos e relatórios desses eventos iluminam de forma ímpar vários aspectos do otimismo progressista que impregnava a atmosfera da sociedade burguesa em formação. Encontram-se ali expostos o ideal obsessivo do saber enciclopédico e o não menos conhecido europocentrismo, garbosamente fantasiado de cosmopolitismo liberal e altruísta. [...]. ${ }^{27}$
\end{abstract}

O Brasil não poderia ficar de fora dessas mostras, e participou de diversas delas. Melhor ainda, Manáos, “orgulho da civilização”, referencial de progresso, não deveria mesmo perder a oportunidade de mostrar ao mundo sua ascensão em meio a selva.

Sandra Pesavento, afirma que nas exposições,

[...] o mundo pois se mobilizava para um encontro universal em nome do progresso e da concórdia entre os povos, da instrução e do divertimento das trocas comerciais e da exibição de novidades, etc [...] a exposição procura transmitir valores e ideias, como a solidariedade entre as nações e a harmonia entre as classes, a crença no progresso ilimitado e a confiança nas potencialidades do homem no controle da natureza, afé nas virtudes da razão e no caráter positivo das maquinas, etc., etc. Por outro lado, a exposição busca ocultar a exploração do homem pelo homem, a concorrência imperialista entre as nações e o processo de submissão do trabalhador à máquina. ${ }^{28}$ 
Dentre as diversas Exposições Universais, a do ano de 1893, realizada em Chicago, é bastante relevante para Manáos. Nesta Manáos foi apresentada pelo Álbum: “The City of Manáos and the Country of Rubber Trees", que se traduz em "A Cidade de Manáos e o País das Seringueiras" 29 , era um souvenir, divulgada na Exposição.

Desde a capa, o álbum desperta curiosidades e encantamentos. Vemos nesta imagem, o seringueiro em seu ofício, cercado pela vegetação e o rio. As letras, desenhadas de maneira pitoresca, chamam atenção.

No seu interior, vemos de tudo um pouco, desde elementos nativos como variedades da fauna e flora, os prédios de Manáos que começavam a surgir neste período, e os índios, sim o índio aparece neste álbum, porém de uma forma longínqua, afastada, o que fica em evidência é a belle époque, a reurbanização da cidade, as pompas que a economia gomífera proporcionou.

Entre a cidade mostrada, e a cidade real, neste álbum temos uma distância expressiva, pois, essas fotografias de paisagens, com a participação em exposições universais, desperta uma sensação de "não estar no todo", de "iluminar uma parte escurecendo as demais. "30 Sim, não é toda a Manáos que aparece neste álbum, até porque, quem não se enquadrava nas normas, no discurso do belo e organizado não iria ser bem visto em uma exposição progressista, que precisa atrair investidores na cidade.

Figura 04: "Remedios Street-Manáos

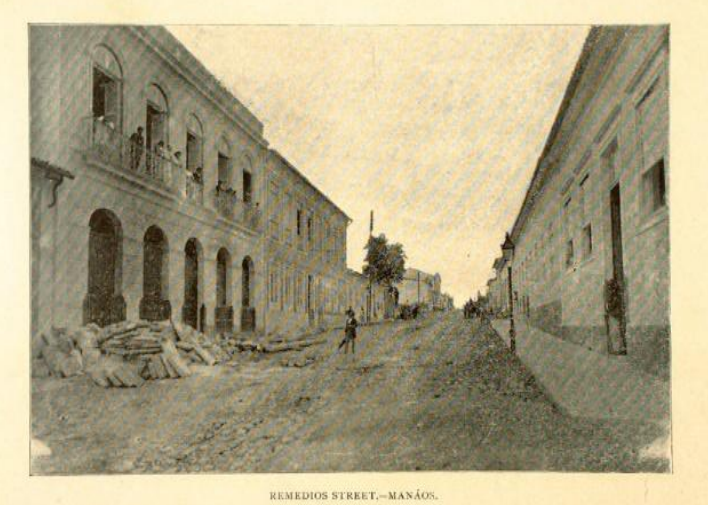

Fonte: Álbum: The city of Manáos and the country of rubber tree. Acervo: IGHA.
Figura 05: “Lyceum - Manáos

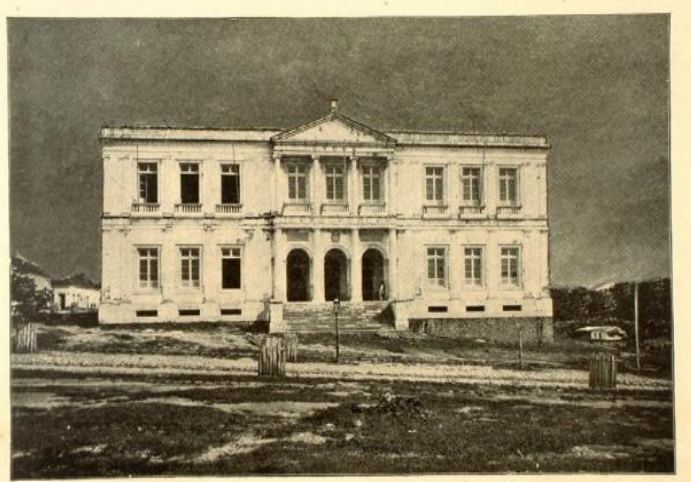


Figura 06: "Bank of Manáos"

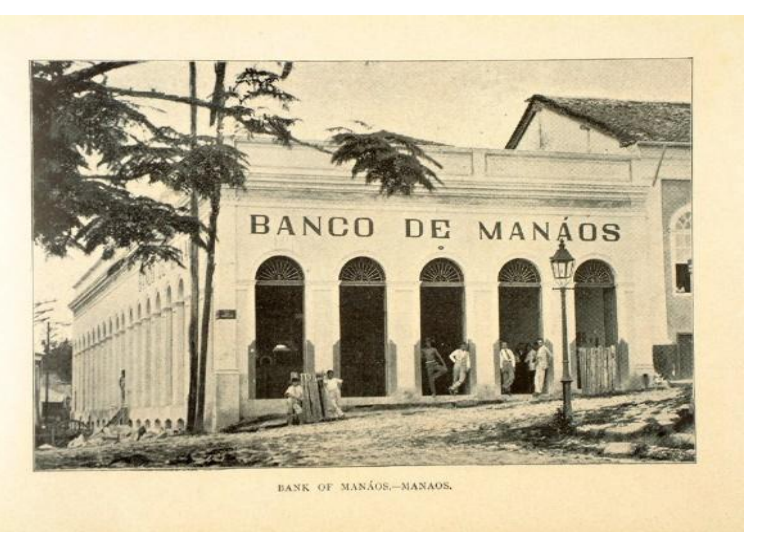

Figura 07: "State Treasury"

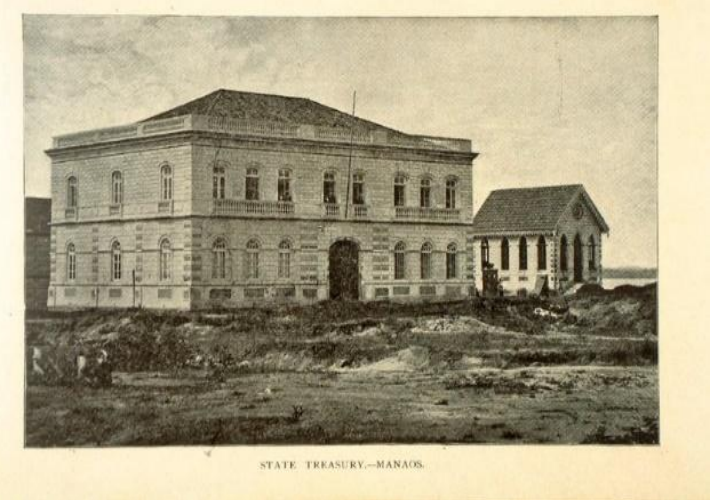

Fonte: Álbum: The city of Manáos and the country of rubber tree. Acervo: IGHA.

Estas figuras (figuras de 04 a 07) mostram claramente os prédios públicos, em construção ou já erguidos. Isso pretendia mostrar a que moldes, Manáos estava sendo reurbanizada. A figura 04, mostra a Rua dos Remédios, percebe-se o estilo europeu das casas, a veste das pessoas, e nota-se que ainda está em construção uma vez, que há entulhos de obra presente na foto. A figura 05 mostra o antigo Lyceum, atual Colégio Amazonense Dom Pedro II. Vejamos o entorno, há casas de madeira pequenas, comparadas ao tamanho do prédio do Lyceum, ruas sem pavimentação. Essas imagens belas queriam fascinar quem as visse, porém, “[...]. A imagem bela, simulacro da realidade, não é a realidade histórica em si, mas traz porções dela traços, aspectos, símbolos, representações, dimensões ocultas, perspectivas, induções, códigos, cores e formas nela cultivadas. [...]." 31

Esse discurso de progresso, era estampado neste álbum, com o intuito de representar o belo, o ideal, porém a realidade nem sempre correspondia ao retratado no álbum. Era imperativo que se mostrasse apenas o belo, mas como lemos acima o belo não é a realidade em si, uma vez que desta fase, não foram todos os ângulos, os contrastes que existiam.

Queremos destacar que a cidade de Manaus durante o final do oitocentos, estava vivenciando o boom advindo pela extração da goma elástica e como essa enriquecera uma parcela da sociedade de então. Mas, não foi toda a sociedade que usufruiu dessa riqueza, apenas uma elite gozou desses louros. Segundo o discurso oficial, a cidade toda se enriquecera, ideia corroborada pela grande divulgação da cidade por meio das fotografas que apenas destacavam o esplendor da cidade festa. Todas as imagens, fazem uma alusão a cidade como sendo de raízes estrangeiras, mas vê-se índios que são ligados ao exotismo, ao diferente, ao fantasioso. Devemos ter em mente que, 
Para compreender a fotografia como fonte histórica é importante levar em conta os usos sociais que agenciaram o invento fotográfico ao longo dos séculos XIX e XX e consolidaram acervos importantes para a pesquisa.

Quando a fotografia ingressou no mercado, em versões técnicas variadas, lançadas em pequenos lapsos de tempo entre 1839 e 1850, rapidamente nela se identificou a capacidade de atender as mais diferentes demandas sociais. [...] . ${ }^{32}$

Um dos objetivos da fotografia no século XIX, limiar do XX, era o de seduzir, apresentar ao mundo uma localidade pouco conhecida, era divulgar, publicar, Manáos era apresentada como uma cidade viva, celebrada, civilizada e opulenta, como vemos na imagem a seguir

Figura 08: "Manáos Theatre-

In Course of Construction"

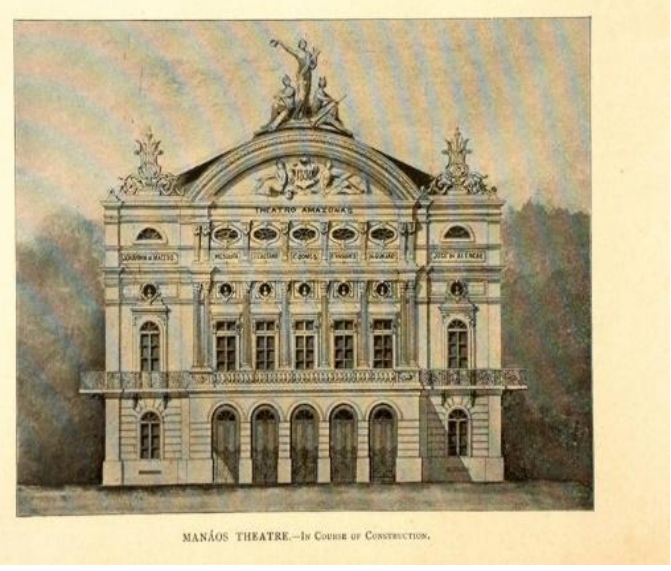

Fonte: Álbum: The city of Manáos...
Figura 09: Fachada do Teatro Amazonas

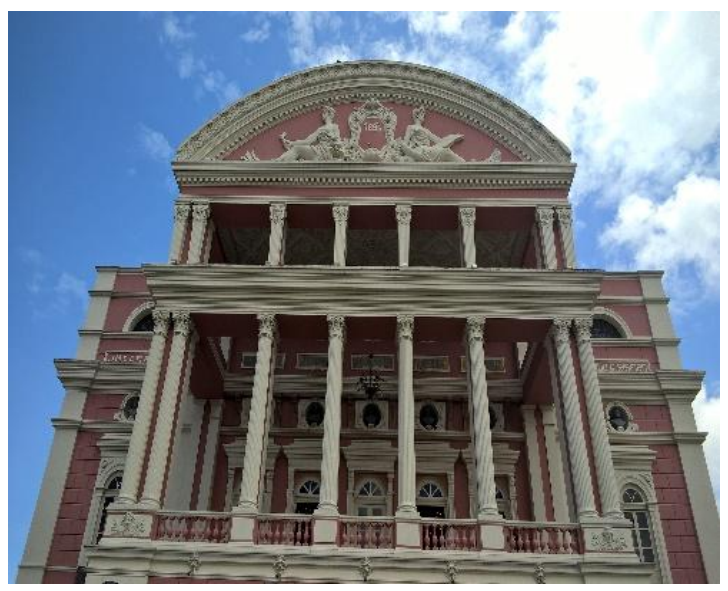

Fonte: BRAGA, Bruno, 2016

A figura 08, se trata de uma fotografia de uma provável fachada para o Teatro Amazonas, opulenta e suntuosa. Sobre esta imagem, Otoni Mesquita informa-os que,

A referida ilustração é um projeto de fachada do Teatro Amazonas que era bastante semelhante à fachada atual, notando-se no entanto, a ausência da cúpula e a presença de alguns elementos decorativos colocados sobre a platibanda e sobre o frontão [...] 33

Logo, vemos através desta imagem como poderia ter sido a atual fachada do Theatro. Porém, como vemos na figura 09, a fachada fora substituída. 
Há grande quantidade neste álbum de fotografias relativas à região do Rio Purus, formando como que uma linha diferencial, de grande distância entre as vivências de Manáos com as demais localidades do Amazonas. Vê-se nestas imagens a realidade dessa região. Mas o destaque do álbum é para a cidade. Ana Daou, nos mostra que neste álbum,

[...] é significativo que o título privilegie a cidade, contrapondo-se às representações mais vulgarizadas sobre o Amazonas, referidas a natureza hegemônica e à população indígena. Embora a dimensão dos recursos, das riquezas naturais esteja presente no título e em grande parte das imagens, é notável a intenção de apresentar a cidade, suas instituições e as melhorias urbanas. As imagens consagradas neste álbum, sintetizam a cidade como esta se apresentava no final do período monárquico, de tal modo que as duas "panorâmicas de Manaus", tomadas do rio, mostram a cidade voltada para as águas, discreta intervenção na natureza circundante. Seguem-se imagens pontuais de uma cidade que se "civilizava" e dispunha das instituições como sinal deste fato, assim como de instrumentos de domínio e controle do espaço social: o palácio do governo, a estação de tratamento de água, uma ponte de ferro, a fachada do Teatro em construção, as obras de calçamento e alinhamento das ruas, o mercado público, o asilo. A esta sequência, em que a cidade como conjunto é quase uma e na qual ela se apresenta em imagens isoladas em que faltam pessoas e inexistem sinais da vida cotidiana, segue-se outra série relacionada ao interior da Província: entre elas, a do rio Purus, de onde na época (1890) advinha boa parte da riqueza do estado. $[\ldots]^{34}$

Pelas figuras do álbum, verificamos uma postura de oposição dos governantes em apresentar ao mundo um local onde ainda os indígenas formavam a maior parte do contingente humano. Mas, pela leitura das imagens presentes, vemos que também, há uma tentativa de apresentar ao mundo Manaus como exemplo de civilização, como local de civilização. Que a cidade virara naquele momento um canteiro de obras não há discordância, mas a ausência de elementos e fazeres indígenas na cidade é uma tentativa frustrada.

Figura 10: "Panorama of Manáos - River Front"

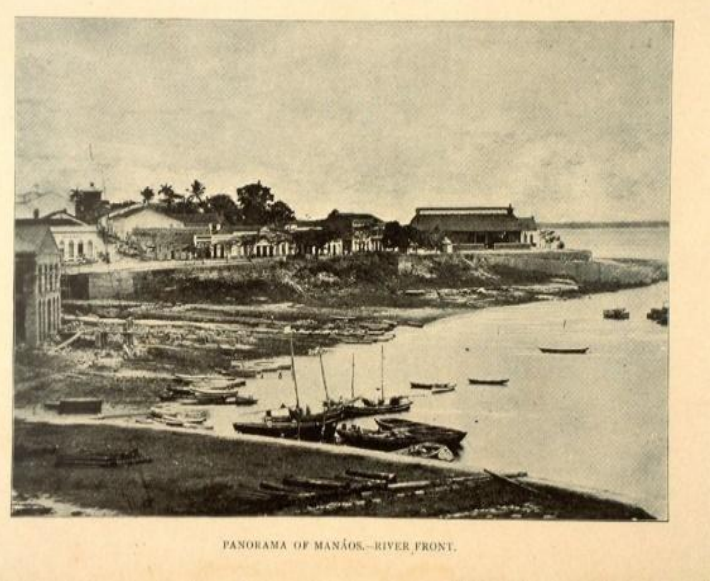

Figura 11: "Panorama of Manáos - River Front"-

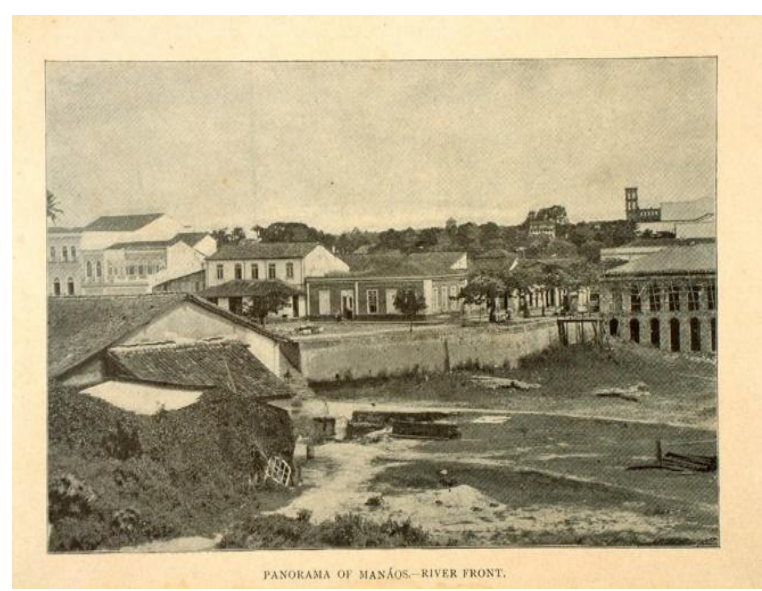

Fonte: Álbum: The city of Manáos and the country of rubber tree 
Destes panoramas de Manáos de frente ao Rio, percebemos a topografia do espaço, a construção das casas, uma cidade com características ribeirinhas apesar de grande parte de seu espaço estar passando por uma ressignificação, a paisagem e a topografia exalam as características das cidades amazônicas.

Figura 12: "Axioma - Purus River."



Axtown-preans siven
Figura 13: "Rubler Gatherers Towing Canol Up Purus Riber."

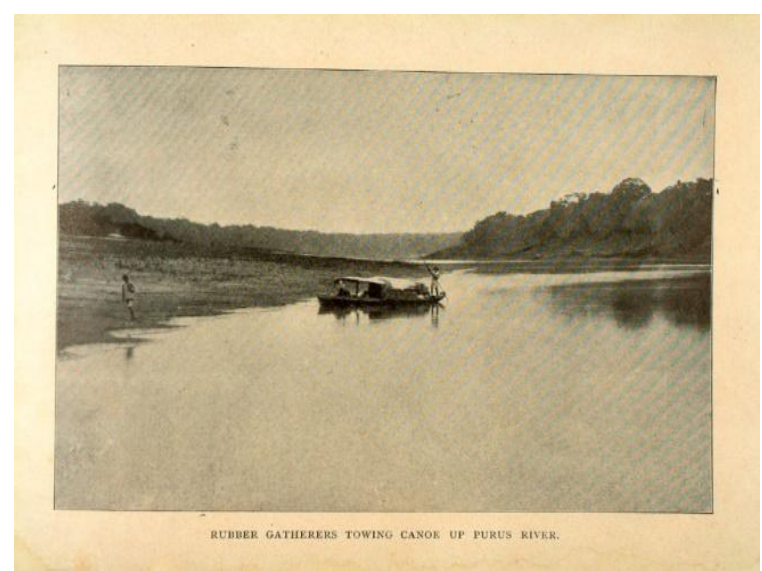

Fonte: Álbum: The city of Manáos and the country of rubber tree

Em detrimento a cidade de Manaus que fora a apresentada como uma cidade que exalava civilização e urbanidade, o "país das seringueiras", seria um grande interior, uma região onde tudo se estava por fazer, que mantinha-se ainda com latentes características rurais cria-se assim o discurso que a cidade de Manaus era um centro civilizador, e o entorno da Província do Amazonas ainda se encontrava em fase ruralista. Porém, se trata de um discurso, pois a fase luxo e alegre da cidade de Manaus não foi acessível, nem vivenciada por todos.

Criação de gado, casas cobertas de palha e estrutura em tábuas, pessoas com trajes simples, sem eletricidade, sem praças, sem jardins, sem teatro, meio de transporte: canoa, grande porção de água em rio, etc., são características típicas da vida rural apresentada na imagem do álbum, era como se Manáos fosse consolidada como centro urbano civilizado, distante de todo o "atraso" da vida rural, campestre, porém em grandes áreas de Manáos, essas práticas sociais, mesmo impedidas pela Legislação, ocorriam, pois, a grande maioria da população residente na cidade da borracha era índia, tapuia ou mameluca, e à belle époque não alcançou a todos. A grande contradição apresentada é que a pelo discurso do álbum Manaus era um lugar à parte, diferente do restante do Amazonas. A imprensa local, 
diariamente apresenta-nos a visão, as vivências daqueles que pouco ou quase nada usufruíram do boom da borracha, muitos afirmavam que,

\begin{abstract}
A impressão que se tem ao chegar a Manaus é deplorável. A capital do grande Estado, em que há na natureza opulenta, na sombrosa fertilidade de suas terras, não um, mas muitos potosis, mais parece uma cidade em abandono.

É um horror! A cidade está cheia de indigentes, que vivem a sol e a chuva, pelos jardins e por todos os cantos da cidade, muitos atacados de febre e beribéri! Morrese de fome em Manaus, é esta a verdade. ${ }^{35}$
\end{abstract}

De fato, pela análise de outras fontes do período, percebemos a cidade com uma contradição imensa, pois se de um lado surgiam grandes e ornados edifícios, de outro lado havia mendicância, prostituição, e falta de canalização em grande parte da cidade. Havia um cenário paradoxo onde uma cidade era divulgada, outra tentava-se esconder.

Visualizamos a grande distância entre a cidade mostrada, divulgada ao mundo e uma outra cidade. Vale ressaltar que, acredito que o poder ao mostrar no álbum índios e afirmar que são habitantes da região do Rio Purus, queriam evidenciar que os índios estavam longe de Manáos. Geograficamente falando, a região do Purus é bastante distante de Manaus, o que leva crer que se criou um discurso de que em Manáos não existiam indígenas, nem tapuias, houve um "branqueamento da vitrine", uma vez que,

Como resultado das mudanças ocorridas no final do séc. XIX, surgia com o novo século uma outra cidade, que pode ser interpretada como a imagem da vitrine instalada, resultado de uma série de transformações. Todo processo de mudanças, com suas obras públicas, a introdução de novos costumes e a adoção de modernos serviços públicos podem ser simbolicamente compreendidos como um "rito de passagem" do processo de branqueamento através do qual a cultura local despia-se das tradições de origem indígena e vestia-se com características ocidentais. ${ }^{36}$

A cidade que era predominantemente indígena foi posta na tentativa de ocidentalização, evocando um espírito e ornamentos estrangeiros. Mas, desaparecer um fazer, e características culturais de uma cidade é uma árdua tarefa, mesmo que se tenha uma grande propaganda, as cidades mantêm suas práticas cotidianas. Tornou-se imperativo "desaparecer" com os índios de Manaus, visto que a cidade se tornava cada vez mais branca, o interessante é perceber que mesmo assim, o poder público, pôs no álbum da Exposição de Chicago, fotos de índios, talvez para apenas utilizar o índio como uma forma de excentricidade, uma vez que nas exposições internacionais, o diferente, o exótico despertava a atenção. No caso de utilizar indígenas, possivelmente o governo pretendia "atrair olhares", de aventureiros do além-mar para a pouco explorada Amazônia de então. 
Figura 14: "Pamary Girl-Purus River"

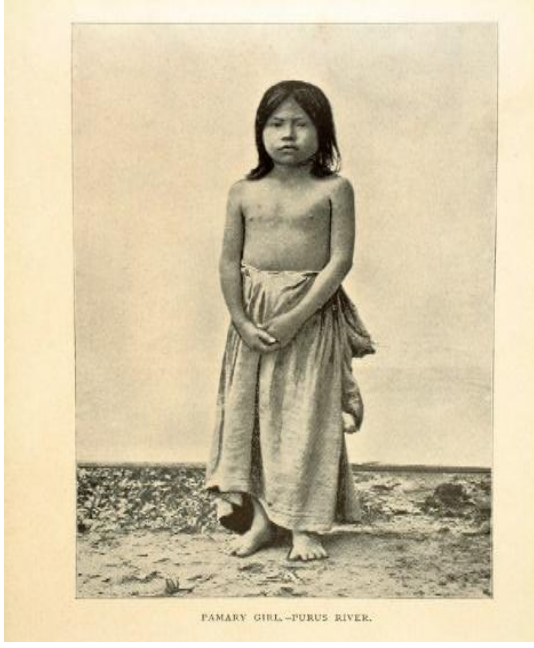

Figura 15: "Jamamady's Indian Chief-Purus River"

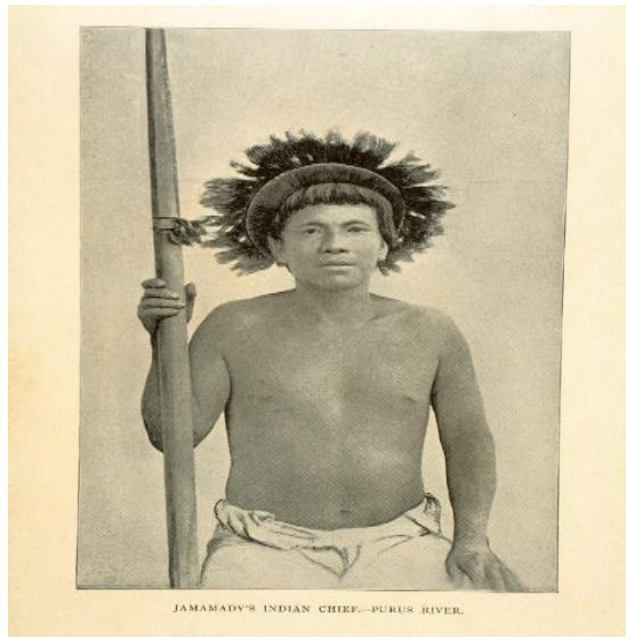

Fonte: Álbum: The city of Manáos and the country of rubber tree.

As figuras acima (Figs. 14 e 15), apresentam-nos dois índios fotografados, presentes no álbum The city of Manáos and the country of rubber tree, o autor ou idealizador do álbum, faz questão de destacar em sua legenda, que os mesmos são índios da Região do Rio Purus (Purus River), pois em Manáos, segundo o discurso "não existiam índios”, coisa que não tinha verossimilhança. Esse Álbum, apresenta-nos uma versão do pensamento acerca da sociedade manauara e seu imaginário. Manaus era festejada e apresentada ao mundo como "Capital da Borracha", mas não era o "Paiz das Seringueiras", nesse sentido, o álbum se propunha a mostrar a Cidade de Manáos como um oásis, o centro civilizado de um grande país que era o das Seringueiras. Nesse sentido, concordo com Ana Daou quando esta afirma que:

\begin{abstract}
Na passagem do século XIX para o século XX, observa-se também o esforço de construção e divulgação de uma nova imagem da cidade por parte da elite, que dispunha finalmente dos sinais de civilização expressivos do progresso. Operava-se um distanciamento em relação às descrições da pequena cidade divulgadas pelos relatos dos viajantes ou ainda registradas nos relatórios de presidentes de Província, nos quais havia sempre muito a ser feito em termos de melhorias e embelezamentos urbanos. [...]. Naquele momento, a elite e seus representantes concentravam-se na promoção de um distanciamento das imagens que consagravam $o$ Amazonas, aquelas que destacavam a valorização dos produtos $e$ as potencialidades da natureza. ${ }^{37}$
\end{abstract}

Logo, o álbum, também tinha uma função de propagar e apresentar uma cidade idealizada, bonita, moderna, civilizada, e distante de todo o restante do território da Amazônia, Manáos ostentava assim, o "orgulho das civilizações”, uma cidade moderna, que 
outrora havia sido uma aldeia. Nas fotografias dos índios acima, vemos sua postura, ou melhor a feição que deveriam transmitir a quem os vesse possivelmente, estavam se expondo a esta situação pois mereceram atenção por parte do autor das fotografias, pois a fotografia é aquilo que desperta a atenção por parte do forasteiro.

\section{Considerações Finais}

Com toda essa discussão, pretendemos mostrar como o poder público criara o mito, de que na cidade de Manáos, no período analisado, não era possível se ter índios, ou mais, se viver com práticas de saberes indígenas. Pelo que já foi posto até aqui, visualizamos que a cidade mostrada era uma, e na cidade das vivências, havia uma distância demasiada da cidade vivida que exalava em sua sociabilidade saberes, fazeres sabores e crenças indígenas.

No ano de 1900, houve outra exposição, essa mais luxuosa e exuberante, era a Exposição de Paris, por se realizar na cidade luz, modelo a ser seguido, o Amazonas, em especial Manáos, devia estar ali representada. O Jornal Commercio do Amazonas, do dia 12 de junho de 1898, em uma matéria intitulada "A Amazonia em Pariz”, narra uma rivalidade bem particular da região: Pará contra Amazonas. O autor da matéria, procura evidenciar que não é justo o Pará expor prédios e monumentos mais estrangeiros que nativos, e o Amazonas, ficar com o atrasado conteúdo típico da região, nas palavras do autor:

[...] o Amazonas, a nossa prodigiosa terra, nada tem que expor a não ser os desenhos dos palácios que pretende construir, das pontes, reservatório e outros melhoramentos materiais desta capital, pois os seus produtos cifram-se na sinfonia elástica, na castanha e no cacau já muito conhecidos e para os quais não precisamos mais de reclames, porque felizmente não temos para eles competidores nos mercados estrangeiros.

Exibir flechas, arcos e outros objetos indígenas isso já passou a ser ridículo.

Madeiras? Mas para que expor madeiras se nós as importamos por não termos quem se incumba de arrancá-las das majestosas matas virgens, que só nos animamos a explorar para extrair a seringa?! [... $]^{38}$

O objetivo era apresentar uma cidade urbanizada, moderna, branca e civilizada, mostrar elementos da cultura indígena era retrógrado, e já era uma coisa sem importância, a própria madeira era importada, pois não havia trabalhadores para extrair, para a elite só interessava a extração da seringa e, evidentemente o enriquecimento para levar adiante seus interesses peculiares que propunham entre outras, a reconfiguração espacial e cultural da cidade! 


\section{Notas}

${ }^{1}$ Cf. DAOU, Ana Maria. A Belle Époque Amazônica. $3^{\mathrm{a}}$ ed. Rio de Janeiro: Jorge Zahar Editor, 2004

${ }^{2}$ Ler mais sobre a Paris de Haussman em BEMJAMIN, Walter. Paris, a capital do século XIX. In: Espaço e Debates. Revista de Estudos Regionais e Urbanos, $\mathrm{n}^{\circ}$ 11, São Paulo - 1984.

${ }^{3}$ COELHO, Geraldo Mártires. Na Belém da belle époque da borracha (1890-1010): dirigindo os olhares. Escritos (Fundação Casa de Rui Barbosa), v. 5, p. 141, 2011.

${ }^{4}$ Idem.

${ }^{5}$ BIARD, François Auguste. Deux années au Brésil, Hachette, Paris, 1862

${ }^{6}$ MARCOY, Paul. Viagem pelo Rio Amazonas. Trad. de Antônio Porro. Manaus. Edições do Governo do Estado do Amazonas / Secretaria de Estado da Cultura, Turismo e Desporto. Editora da Universidade do Amazonas, 2001. p. 167.

${ }^{7}$ SANTOS, Douglas. O que é Geografia? Apostilado, 2007.

${ }^{8}$ SANTOS, Milton. Pensando o espaço do homem. 4. ed. São Paulo: Hucitec, 1997, p., 37.

${ }^{9}$ MARCOY, Paul. Viagem pelo Rio Amazonas. Trad. de Antônio Porro. Manaus. Edições do Governo do Estado do Amazonas / Secretaria de Estado da Cultura, Turismo e Desporto. Editora da Universidade do Amazonas, 2001.p. 168

${ }^{10}$ AMAZONAS, Lourenço da Silva Araújo e. (1852). Dicionário Topográfico, Histórico, descritivo da Comarca do Alto Amazonas. Recife. Meira Henrique Nova - Edição Fac-similar; Manaus: Associação Comercial do Amazonas - ACA - 1984. (Coleção Hiléia Amazônia, "1".

${ }^{11}$ Fortaleza de São José da Barra do Rio Negro foi uma fortificação militar portuguesa do século XVII, que dera origem mais tarde a Cidade da Barra do Rio Negro, e no século XIX, mudara de nome e passou a ser chamada de Manáos. A maior parte da população citadina era indígena os relatos do período evidenciam isso. Com a denominação de Manáos, a população permaneceu com essa predominância. Ao decurso do século XIX, de fato, a população veio a se reconfigurar com a vinda de empresários e agenciadores da borracha no além-mar. Mas também é fato que a presença indígena nunca foi nula em Manaus até nossos dias.

${ }^{12}$ AGASSIZ, Louis. AGASSIZ, Elisabeth Cary. Viagem ao Brasil: 1865-1866. Trad. de João Etienne Filho. Belo Horizonte: Ed. Itatiaia; São Paulo, Ed. Da Universidade de São Paulo, 1975.p.127 - grifos meus -.

${ }^{13}$ Esta imagem está presente na obra: Deux années au Brésil. Local de Publicação: Paris: Librairie de L. Hachette et $C$. Ano de Publicação: 1862.Descrição Física: 1 grav. pb; gravura em madeira, dimensões da grav.: 11,2 x 16,3 cm em f. 24,0 x 15,0 cm; dimensões da imagem: 2269 x 1547 pixels; 300 dpi (resolução)

${ }^{14}$ COSTA, Hideraldo Lima da. "Amazônia: Paraíso dos Naturalistas". In: Amazônia em cadernos. Manaus: EDUA nº 06, 2000 p. 242.

${ }^{15}$ Os registros possuem uma visão instigante e aguçante. Percebemos nos seus descritos o cotidiano da população local. Podemos perceber etnocentrismo em suas falas. Antônio Emílio Morga, na obra "Nos Subúrbios do Desejo: masculinidade e Sociabilidade em Nossa Senhora do Desterro no Século XIX" (Manaus, EDUA, 2009), nos diz que ao vivenciarem o cotidiano da população, "os viajantes foram partícipes na construção das práticas de sociabilidade entre eles e a comunidade" (p. 30), em Manaus acontece algo parecido à medida que tais viajantes irão praticar hábitos que são característicos da cultura nativa, mesmo classificando a cultura local como inferior à sua.

${ }^{16}$ Ibid. MARCOY, 2001, p. 169.

${ }^{17}$ BERMAN, Marshall. Tudo que é sólido desmancha no ar: A aventura da Modernidade. Trad. de Carlos Felipe Moisés e Ana Maria L. Toratti. São Paulo: Companhia das Letras, 1986, p. 15.

${ }_{18}^{18}$ Idem, p. 15.

${ }^{19}$ MESQUITA, Otoni. Manaus História e Arquitetura (1852-1910). $3^{\mathrm{a}}$ ed. Manaus: Editora Valer / Prefeitura de Manaus / UNINORTE, 2006, p. 29.

${ }^{20}$ CERTEAU, Michel de. A Invenção do Cotidiano 01: Artes de Fazer. Trad. de Ephrain Ferreira Alves. Petrópolis, RJ; Vozes, 2012, p., 39.

${ }^{21}$ Em Manaus, as práticas foram modificadas, ressignificadas por sobrevivência. A resistência que me refiro é política, pois a cultura não é uma característica fixa e intransferível.

${ }^{22}$ AGASSIZ, op. cit. p. 167.

${ }^{23}$ VILLANOVA, Simone. Pescas, Piqueniques, Banhos, a Cultura e os Lazeres Locais no olhar dos viajantes do século XIX. In: CARVALHO JÚNIOR, Almir Diniz. NORONHA, Nelson Matos de. (Orgs.). A Amazônia dos Viajantes: História e Ciência. Manaus: Universidade Federal do Amazonas, 2011. p. 140.

${ }^{24}$ DIAS, Edinea Mascarenhas. “A Ilusão do Fausto: Manaus, 1890-1920”, 2ª ed. Manaus: Valer, 2007. p. 119.

${ }^{25}$ Idem, 2007, loc. cit. 


\footnotetext{
${ }^{26}$ HARDMAN, Francisco Foot. Trem Fantasma: a Modernidade na Selva.São Paulo. Companhia das Letras, 1988, p. 49.

${ }^{27}$ Idem, 1988, p.p. 49, 50.

${ }^{28}$ PESAVENTO, Sandra Jatahy. Exposições Universais: Espetáculos da Modernidade do Século XIX. São Paulo: HUCITEC, 1997, p. 13 e p. 44.

${ }^{29}$ The City of Manáos and the country of rubber trees. (Álbum souvenir distribuído na Exposição de Chicago em 1893). Sem local, editora e data de impressão - Acervo do Instituto Geográfico e Histórico do Amazonas IGHA.

${ }^{30}$ MAUAD, Ana Maria. Imagem e Autoimagem do Segundo Império. In: NOVAIS, Fernando A. (coord.) ALENCASTRO, Luiz Felipe (org. do vol.). História da Vida Privada no Brasil: Império: a corte e a modernidade nacional. Vol. 02. São Paulo, Companhia das Letras, 1997, p. 187.

${ }^{31}$ PAIVA, Eduardo França. História \& Imagens. $2^{\mathrm{a}}$ ed. Belo Horizonte: Autêntica, 2006, p.p. 18 e 19.

${ }^{32}$ LIMA, Solange Ferraz e CARVALHO, Vania Carneiro de. Fotografias: Usos Sociais e Historiográficos. In: PINSKY, Carla Bassanezi e LUCA, Tania Regina de. (Orgs.). O historiador e suas Fontes. São Paulo: Contexto, 2011, p. 29 - grifos meus -.

${ }^{33}$ MESQUITA, 2006, op. cit., p. 215.

${ }^{34}$ DAOU, 2014, op. cit., p., 132, grifos meus.

35 JORNAL Correio do Norte, de 3 de fevereiro de 1906 - Matéria: “A Miséria no Amazonas”, cartas. Acervo: Instituto Geográfico e Histórico do Amazonas - IGHA.

${ }^{36}$ MESQUITA, 2006. Op. Cit. p. 145.

${ }^{37}$ DAOU, 2014, Op. Cit., p.p., 128, 129. Grifos meus.

38 JORNAL Commercio do Amazonas. Ano XXX, Nº 203. Domingo, 12 de julho de 1898. Manáos, 1898 grifos meus - ACERVO: Biblioteca Nacional do Rio de Janeiro.
}

\section{Referências Bibliográficas}

AGASSIZ, Louis. AGASSIZ, Elisabeth Cary. Viagem ao Brasil: 1865-1866. Trad. de João Etienne Filho. Belo Horizonte: Ed. Itatiaia; São Paulo, Ed. Da Universidade de São Paulo, 1975.

AMAZONAS, Lourenço da Silva Araújo e. (1852). Dicionário Topográfico, Histórico, descritivo da Comarca do Alto Amazonas. Recife. Meira Henrique Nova - Edição Facsimilar; Manaus: Associação Comercial do Amazonas - ACA - 1984. (Coleção Hiléia Amazônia, "1".

BEMJAMIN, Walter. Paris, a capital do século XIX. In: Espaço e Debates. Revista de Estudos Regionais e Urbanos, nº 11, São Paulo - 1984.

BERMAN, Marshall. Tudo que é sólido desmancha no ar: A aventura da Modernidade. Trad. de Carlos Felipe Moisés e Ana Maria L. Toratti. São Paulo: Companhia das Letras, 1986.

BIARD, François Auguste. Deux années au Brésil, Hachette, Paris, 1862.

CERTEAU, Michel de. A Invenção do Cotidiano 01: Artes de Fazer. Trad. de Ephrain Ferreira Alves. Petrópolis, RJ; Vozes, 2012.

COELHO, Geraldo Mártires. Na Belém da belle époque da borracha (1890-1010): dirigindo os olhares. Escritos (Fundação Casa de Rui Barbosa), v. 5, 2011.

COSTA, Hideraldo Lima da. "Amazônia: Paraíso dos Naturalistas". In: Amazônia em cadernos. Manaus: EDUA n 06, 2000.

DAOU, Ana Maria. A Belle Époque Amazônica. $3^{\mathrm{a}}$ ed. Rio de Janeiro: Jorge Zahar Editor, 2004.

DIAS, Edinea Mascarenhas. "A Ilusão do Fausto: Manaus, 1890-1920”, 2a ed. Manaus: Valer, 2007.

HARDMAN, Francisco Foot. Trem Fantasma: a Modernidade na Selva.São Paulo. Companhia das Letras, 1988. 
JORNAL Commercio do Amazonas. Ano XXX, № 203. Domingo, 12 de julho de 1898. Manáos, 1898 - grifos meus - ACERVO: Biblioteca Nacional do Rio de Janeiro.

JORNAL Correio do Norte, de 3 de fevereiro de 1906 - Matéria: "A Miséria no Amazonas", cartas. Acervo: Instituto Geográfico e Histórico do Amazonas - IGHA.

LIMA, Solange Ferraz e CARVALHO, Vania Carneiro de. Fotografias: Usos Sociais e Historiográficos. In: PINSKY, Carla Bassanezi e LUCA, Tania Regina de. (Orgs.). $O$ historiador e suas Fontes. São Paulo: Contexto, 2011.

MARCOY, Paul. Viagem pelo Rio Amazonas. Trad. de Antônio Porro. Manaus. Edições do Governo do Estado do Amazonas / Secretaria de Estado da Cultura, Turismo e Desporto. Editora da Universidade do Amazonas, 2001.

MARCOY, Paul. Viagem pelo Rio Amazonas. Trad. de Antônio Porro. Manaus. Edições do Governo do Estado do Amazonas / Secretaria de Estado da Cultura, Turismo e Desporto. Editora da Universidade do Amazonas, 2001.

MAUAD, Ana Maria. Imagem e Autoimagem do Segundo Império. In: NOVAIS, Fernando A. (coord.) ALENCASTRO, Luiz Felipe (org. do vol.). História da Vida Privada no Brasil: Império: a corte e a modernidade nacional. Vol. 02. São Paulo, Companhia das Letras, 1997.

MESQUITA, Otoni. Manaus História e Arquitetura (1852-1910). $3^{\mathrm{a}}$ ed. Manaus: Editora Valer / Prefeitura de Manaus / UNINORTE, 2006.

PAIVA, Eduardo França. História \& Imagens. 2a ed. Belo Horizonte: Autêntica, 2006.

PESAVENTO, Sandra Jatahy. Exposições Universais: Espetáculos da Modernidade do Século XIX. São Paulo: HUCITEC, 1997.

SANTOS, Douglas. O que é Geografia? Apostilado, 2007.

SANTOS, Milton. Pensando o espaço do homem. 4. ed. São Paulo: Hucitec, 1997.

The City of Manáos and the country of rubber trees. (Álbum souvenir distribuído na Exposição de Chicago em 1893). Sem local, editora e data de impressão - Acervo do Instituto Geográfico e Histórico do Amazonas -IGHA.

VILlanOVA, Simone. Pescas, Piqueniques, Banhos, a Cultura e os Lazeres Locais no olhar dos viajantes do século XIX. In: CARVALHO JÚNIOR, Almir Diniz. NORONHA, Nelson Matos de. (Orgs.). A Amazônia dos Viajantes: História e Ciência. Manaus: Universidade Federal do Amazonas, 2011. 